\title{
Formulation and Optimization of Orodispersible Tablet of Loratadine Using Box Behnken Design
}

\author{
Kundawala Aliasgar1*, Patel Pratik², Chauhan Khushbu1', Desai Anjali ${ }^{1}$, Kapadia Dhwani1 \\ ${ }^{1}$ Indukaka Ipcowala College of Pharmacy, New Vallabh vidyanagar-388121, Gujarat, India \\ ${ }^{2}$ A. R College of Pharmacy and G.H Patel Institute of Pharmacy, Vallabh vidyanagar-388120, Gujarat, India
}

\begin{abstract}
In present study Orodispersible tablets (ORDT) of Loratadine were prepared and optimized. Solid dispersion of Loratadine- $\beta$ cyclodextrin complex were prepared and used in preparation of Orodispersible tablets. Various super-disintegrating agent like Cross carmellose sodium, Cross povidone and Kyron T-314 were employed for faster disintegrating effect. The $2^{4}$ factorial and Box-Behnken design were utilized to optimize the tablet formulation. The Orodispersible tablet of Loratadine was optimized by Box Behnken Design, where concentrations Kyron T 314, CRP and Pearlitol SD200 were employed and its effect on Disintegration time (DT), Wetting time (WT) and \% drug release at 20 min (Q20) was evaluated. Precompression parameters like angle of repose, bulk density, \% compressibility, Hausner's ratio was studies. The different batches of Orodispersable tablets were prepared and evaluated for disintegration time, friability, wetting time and drug release studies. Different batches prepared showed disintegration time in the range of $23 \pm 2.52$ to $59 \pm 2.64$, wetting time in between $27 \pm 0.57$ to $66.3 \pm 3.4$, drug release (Q 20) in between $86.1 \pm 0.6$ to $96.7 \pm 0.4$ in $20 \mathrm{~min}$., friability less than $1 \%$ and hardness 3.4 to $4.2 \mathrm{Kg} / \mathrm{cm}^{2}$. The optimized formula when compared with marketed product it showed faster disintegration time and rapid drug dissolution in phosphate buffer 6.8. The solid dispersion of Loratadine not only helped improve in solubility but may also help in taste masking.
\end{abstract}

Keywords: Orodispersible tablets, Loratadine, $\beta$ cyclodextrin Solid dispersion

Article Info: Received 11 July 2019; $\quad$ Review Completed 17 August 2019; Accepted 21 August 2019; Available online 30 Aug 2019

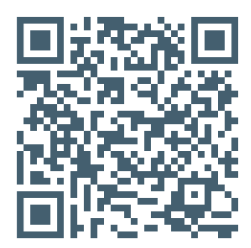

Cite this article as:

Kundawala A, Patel P, Chauhan K, Desai A, Kapadia D, Formulation and Optimization of Orodispersible Tablet of Loratadine Using Box Behnken Design, Journal of Drug Delivery and Therapeutics. 2019; 9(4-A):86-94 http://dx.doi.org/10.22270/jddt.v9i4-A.3402

\section{*Address for Correspondence:}

Dr. Aliasgar Kundawala, Associate Professor, Dept. Of Pharmaceutics and Pharmaceutical Technology, Indukaka Ipcowala College of Pharmacy, B/H GIDC phase 4, Vitthal Udyog nagar, New Vallbh vidyanagar-388121, Gujarat, India

\section{INTRODUCTION}

Tablet stands for most affordable and patient friendly dosage form because of its convenience in self administration, compactness and easy manufacturing. However, in certain conditions tablet offers little inconvenience such as in case of elderly patients, bad ridden patient or in certain medical conditions where faster action in desirable that leads to high incidence of non-compliance and ineffective therapy. Patient convenience and compliance oriented research has resulted in bringing out many safer and newer drug delivery systems. Rapidly disintegrating / dissolving tablet is one of such examples. Fast disintegrating tablets are gaining prominence as new drug delivery systems. These dosage forms dissolve or disintegrate in the oral cavity within a minute without the need of water or chewing. Orodispersible Tablets (ORDTs) are suitable for numerous indications ranging from migraines (for which rapid onset of action is important), in mental illness (where patient compliance is important for treating chronic ISSN: 2250-1177 indications such as depression and schizophrenia), in motion sickness, sudden episodes of coughing during the common cold, allergic condition and bronchitis. This attribute makes these dosage forms highly attractive product for the pediatric, geriatric and dysphasic patients ${ }^{1-2}$.

Orodispersible tablets usually disintegrate or dissolve rapidly in saliva. Saliva in the mouth coused the tablet to disintegrate within few seconds and get dispersed or dissolved in saliva. In this way the drug is available and absorbed before reaching stomach. This makes the drug avoid first pass metabolism and give faster therapeutic effect. This makes orodispertablet achieve better bioavailability compared to conventional tablet dosage form $^{3-4}$.

The Orodispersible tablets are prepared either by use of superdisintegrants, effervescent approach or by sublimation technique. Various superdisintegrants such as sodium starch glycolate, crosspovidone, cross carmellose sodium, resins or 
other natural polymers like husk are used in preparation of Orodispersible tablets. The superdisintegrating agent basically provides disintegration by swelling, wicking or capillary actions after absorption of water that couses busting of tablet or grabules ${ }^{5}$.

Researchers have worked on ODT formulations for various categories of drugs, which are used for therapy in which rapid peak plasma concentration is required to achieve desired pharmacological response. These include neuroleptics, cardiovascular agents, antihistamines and analgesics. Orally disintegrating tablets are tailor made for these patients as they immediately release the active drug, when placed on the tongue, by rapid disintegration, followed by dissolution of the drug. European pharmacopoeia defines "Orodispersible tablets are uncoated tablets intended to be placed in the mouth where they disperse rapidly before being swallowed". Orodispersible tablets disintegrate within 3 minutes ${ }^{6-7}$. To improve the dissolution and bioavailability of poorly soluble drugs, researchers have employed various techniques, such as micronization, solubilization, salt formation, complexation with polymers, and change in physical form, use of prodrug and drug derivatization, alteration in $\mathrm{pH}$, addition of surfactants ${ }^{8}$

Loratadine is a second generation non sedative antihistamine drug that reduces the effects of natural chemical histamine in the body. Histamine can produce symptoms of sneezing, itching, watery eyes, and runny nose. It is also used in the treatment of allergic skin disorder, specially atopic dermatitis and urticaria, allergic rhinitis, acute coryza, ocular allergies at the dose of $10 \mathrm{mg}$ once a day in adult and $5 \mathrm{mg}$ (if $<30 \mathrm{~kg}$ ) or $10 \mathrm{mg}$ (if $<30 \mathrm{~kg}$ ) in $2-12$ years children ${ }^{9-10}$. It's like other H1-blockers, loratadine competes with free histamine for binding at H1-receptors in the GI tract, uterus, large blood vessels, and bronchial muscle.

Loratadine is a poorly soluble drug and indicated in treatment of allergic rhinitis (AR) and chronic idiopathic urticaria (CIU). The poorly water-soluble drugs often show an erratic dissolution profile in gastrointestinal fluids, which consequently results in variable oral bioavailability. In present study investigation was carried out to prepare Orodispersible tablet of Loratadine using different superdisintegrants at different concentration level to enhance bioavailability and patient compliance.

\section{MATERIAL AND METHODS}

Loratadine (LRD) was kindly provided by Cadila Pharmaceuticals Ltd. India. $\beta$-Cyclodextrin $(\beta-C D)$ was provided by Mercury Lab. Pvt. Ltd., Baroda, India. Pearlitol SD 200 was provided by Roquette pharma, France. Kyron T 314 and Crosspovidone (CRP) was supplied by Corel Pharm Ltd. India. Crosscarmellose sodium (CS) and sodium starch glycolate (SSG) was purchased from Sunrise remedies Pvt. Ltd, India. Magnesium Stearate, aerosol, microcrystalline cellulose and aspartame was purchased from Chemdyes Corporation, Ahmedabad, India. All other reagents used are of analytical grade.

\section{Formulation of orodispersible tablet of Loratadine $-\beta$ cyclodextrin complex.}

The orodeispersabale tablet were prepared by direct compression method. The Loratadine- $\beta$ cyclodextrin solid dispersion was used in preparation of orodispersible tablet. Loratadine is a poorly water soluble drug. The drug $\beta$ cyclodextrin complex was prepared to enhance solubility as described in our previous work ${ }^{11}$. In brief, the complexation of Loratadine with $\beta$-cyclodextrin was formed by kneading method using 1:3 molar ratio respectively. This Loratadine$\beta$ cyclodextrin complex showed solubility of $1720 \mu \mathrm{g} / \mathrm{ml}$. In tablet formulation, all the ingredients were passed through sieve No \#100 before blending. The blend was prepared by mixing all the ingredients and lubricated with magnesium stearate and talc later. The resultant powder blend was then compressed into tablets using $8 \mathrm{~mm}$ flat punch in rotary tablet punching machine. Tablets were evaluated for weight variation, hardness, and friability and disintegration time.

\section{Application of $2^{4}$ factorial design}

$2^{4}$ factorial design was introduced to screen formulation variables that may influence the attributes of orodispersible tablet. In present study four factors, amount of Kyron T-314 (KT)(2-6\%), CRP (5-10\%) Pearlitol SD 200 (15-25\%) and hardness $\left(3-4 \mathrm{~kg} / \mathrm{cm}^{2}\right)$ were taken and tested for 16 runs. Other formulation and process parameters were kept constant. The disintegration time and wetting were taken as response variables. The Design Expert software 8.0.1.7 was used to generate and randomize the design matrix for statistical analysis. The experimental runs were experimented thrice. The disintegration time and wetting time were considered as dependent variables. The design matrix for $2^{4}$ factorial design and various factors involved are shown in Table 1 and 2.

$\mathbf{Y}=\mathrm{b}_{\mathrm{o}}+\mathrm{b}_{1} \mathrm{X}_{1}+\mathrm{b}_{2} \mathrm{X}_{2}+\mathrm{b}_{3} \mathrm{X}_{3}+\mathrm{b}_{4} \mathrm{X}_{4}+\mathrm{b}_{12} \mathrm{X}_{1} \mathrm{X}_{2}+\mathrm{b}_{13} \mathrm{X}_{1} \mathrm{X}_{3}+$ $b_{14} X_{1} X_{4}+b_{23} X_{2} X_{3}+b_{24} X_{2} X_{4}+b_{34} X_{3} X_{4}+b_{123} X_{1} X_{2} X_{3}+$ $b_{124} X_{1} X_{2} X_{4}+b_{134} X_{1} X_{3} X_{4}+b_{234} X_{2} X_{3} X_{4}+b_{1234} X_{1} X_{2} X_{3} X_{4}+$ e

Where $\mathrm{Y}$ is the dependent variable, $\mathrm{b}_{0}$ is the arithmetic mean response of the 16 runs and $b_{i}$ is the estimated coefficient for the factor $\mathrm{X}_{1}, \mathrm{X}_{2}, \mathrm{X}_{3}$ and $\mathrm{X}_{4}$. The main effects $\left(\mathrm{X}_{1}\right.$ and $\left.\mathrm{X}_{2}\right)$ represent the average result of changing one factor at a time from its low to high value. The interaction terms $\left(\mathrm{X}_{1} \mathrm{X}_{2} \mathrm{X}_{3}\right)$ show how the response changes when three factors are simultaneously changed. Layout of design is shown in the Table 2 .

Statistically validity of the model was established on the basis of ANOVA provision provided in the Design Expert software 8.0.1.7. Using 5\% significance level, the model was considered significant, if the p value was less than 0.05 ( $p<$ 0.05 )

\section{Optimization of Loratadine ODT by Box Behnken design}

The optimization of orodispersible tablet formulations containing LCD complex were carried out using three level, three factor Box-Behenken design approach. It is a kind of response surface methodology. Here, significant factors identified from of $2^{4}$ factorial design were subjected further evaluation of at three levels. The design consists of replicated centre points and a set of points lying at the midpoints of each edge of the multidimensional cube that defines the interesting area. Amount of Kyron T-314 (Superdisintegrant), CRP (Superdisintegrant) and Pearlitol SD 200 (pore-forming agent) were selected as three independent variables $\mathrm{X}_{1}, \mathrm{X}_{2}$ and $\mathrm{X}_{3}$, respectively. Other formulation component and process parameters were fixed. Again design Expert 8.1.0.7 was employed to statistically evaluate and randamize design matrix. Disintegration times (R1), Wetting time (R2), Cumulative percentage of drug release at 20 min (R3) and Friability (R4) were taken as response variables. Layout of design is shown in the Table 3. Polynomial models including interaction and quadratic terms were generated for three response variables using multiple linear regression analysis (MLRA) approach.

The general form of the MLRA model is represented as the following equation: 
$\mathrm{R}=\mathrm{b}_{0}+\mathrm{b}_{1} \mathrm{X}_{1}+\mathrm{b}_{2} \mathrm{X}_{2}+\mathrm{b}_{3} \mathrm{X}_{3}+\mathrm{b}_{4} \mathrm{X}_{1} \mathrm{X}_{2}+\mathrm{b}_{5} \mathrm{X}_{1} \mathrm{X}_{3}+\mathrm{b}_{6} \mathrm{X}_{2} \mathrm{X}_{3}+$ $\mathrm{b}_{7} \mathrm{X}_{1}{ }^{2}+\mathrm{b}_{8} \mathrm{X}_{2}{ }^{2}+\mathrm{b}_{9} \mathrm{X}_{3}{ }^{2}$

Where $b_{0}$ is the intercept representing the arithmetic mean of all quantitative outcomes of 17 runs; $b_{1}-b_{9}$ are the coefficients computed from the observed experimental response values of $\mathrm{R} ; \mathrm{X}_{1}, \mathrm{X}_{2}$ and $\mathrm{X}_{3}$ are the coded values of the independent variables; $\mathrm{X}_{1} \mathrm{X}_{2}, \mathrm{X}_{1} \mathrm{X}_{3}, \mathrm{X}_{2} \mathrm{X}_{3}$ are interaction terms and $\left(\mathrm{X}_{1}\right)^{2},\left(\mathrm{X}_{2}\right)^{2},\left(\mathrm{X}_{3}\right)^{2}$ are quadratic terms.

The magnitude of the coefficients represents the relative importance of each factor.

\section{Construction of contour plot}

Contour plots were drawn by using design expert version 8.0.1.7. Four contour plot were drawn, the first contour plot of disintegration time was plotted against amount of Kyron T-314 and CRP, second contour plot of $Q_{20}$ was plotted against amount of Kyron T-314 and CRP, third contour plot of wetting time was plotted against amount of Kyron T-314 and CRP and forth contour plot of friability was plotted against amount of Kyron T-314 and CRP.

\section{Pre-compression parameters.}

The powder properties were evaluated with respect to angle of repose, bulk density, tapped density, hausner ratio and compressibility. All procedures were performed in triplicate.

Angle of repose $(\boldsymbol{\theta})$ : The angle of repose was determined by fixed funnel method where the height of the funnel was kept constant and adjusted in such a way that the apex of heap of the powder touched the funnel. The powder blend was allowed to flow and diameter of cone was measured ${ }^{12}$.

Bulk and Tapped Density: For Bulk density 10gms of powder blend for each formula was taken in measuring cylinder $(50 \mathrm{ml})$ and volume of the powder was measured after mild shaking. In case of tapped density the measuring cylinder was tapped on hard surface at height of $2.5 \mathrm{~cm}^{2}$ until no change in volume was observed. The BD and TBD were calculated by taking mass to volume ratio ${ }^{13}$.

$$
\rho_{\mathrm{o}}=\mathbf{M} / \mathbf{V}_{\mathbf{b}}
$$

Where, $\rho_{\mathrm{o}}$ is bulk density,

$\mathrm{M}$ is mass of the blend and

$\mathrm{V}_{\mathrm{b}}$ is Volume of blend

Compressibility and Hausner's ratio: The compressibility was determined by applying Carr's Compressibility index that uses values of BD and TBD. The flowability of powder blend was determined by Hausner ratio as stated in USP 14

Compressibility was calculated using the following equation:

$$
\% \text { Compressibility }=\rho t-\rho o / \rho t * 100
$$

Where,

$\rho_{\mathrm{t}}$ is the tapped density,

$\rho_{\mathrm{o}}$ is the bulk density

\section{Post compression parameters}

\section{Weight Variation Test}

To study weight variation was performed according to United state Pharmacopoeia (USP). 20 tablets of each formulation batch were taken and weighed on electronic balance. 20 tablets were randomly selected from each batch and weighed individually to check for weight variation.

\section{Thickness}

Five tablets were taken and thickness was measured using varnier calipers by placing tablet between two arms and note down the reading 15

\section{Hardness}

The hardness of five tablets of each batch was measured by Monsanto hardness tester. 5 tablets were randomly selected and subjected for hardness test. The hardness was measured in unit of $\mathrm{kg} / \mathrm{cm}^{2} .15$

\section{Friability}

Friability of the tablet was checked by Roche friabilator. Ten tablets were randomly selected from each batch and weighed. Pre-weighed tablets were placed in a friabilator, which was then operated for $4 \mathrm{~min}$ at $25 \mathrm{rpm}$. Tablets were dedusted and reweighed; the loss in the weight of the tablets was recorded and calculated for percentage change in weigh by following equation 15

\section{$\%$ Friability $=\left[\left(W_{0}-W_{1}\right) / W_{0}\right] 100$}

Where, $\mathrm{W}_{0}$ is initial weight of tablets, $\mathrm{W}_{1}$ final weight of tablets

\section{Drug Content uniformity}

5 tablets were randomly selected, crush in mortar pestle and dissolved in $50 \mathrm{ml}$ of $0.1 \mathrm{~N} \mathrm{HCl}$ in $50 \mathrm{ml}$ volumetric flak. The solution was stirred for $30 \mathrm{~min}$ and filtered. $1 \mathrm{ml}$ of the filtrate was further diluted to $100 \mathrm{ml}$ with $0.1 \mathrm{~N} \mathrm{HCl}$. Absorbance of this solution was measured at $274 \mathrm{~nm}$. Content of LRD was calculated using regression line equation.

\section{Wetting Time}

A piece of filter paper was placed in a petridish with $10 \mathrm{~cm}$ diameter. $10 \mathrm{ml}$ of water (containing water soluble dye Eosin) was added to the petridish. A tablet was carefully placed on the surface of the tissue paper. The time required to wet upper surface was measured as wetting time 16

\section{In-Vitro Disintegration time}

The assessment of the in vitro disintegration profile of orodispersible tablet is very important parameter in development of such formulations. The test was carried out on 6 tablets using tablet disintegration tester (Veego Machinery, India) in distilled water at $37^{\circ} \mathrm{C} \pm 2^{\circ} \mathrm{C}$ was used as a disintegration media and time was noted for complete disintegration of the tablet with no palable mass remaining in the apparatus.

\section{In-vitro Dissolution study}

The release rate Loratadine from Orodispersible tablets was determined using United State Pharmacopoeia (USP) dissolution testing Type II apparatus. The dissolution test was performed using $900 \mathrm{ml}$ of phosphate buffer $\mathrm{pH}$ 6.8, at $37 \pm 0.5^{\circ} \mathrm{C}$ and $50 \mathrm{rpm}$. A sample $(10 \mathrm{ml})$ of the solution was withdrawn from the dissolution apparatus at 2, 4, 6, 10, 15, 20, 25 and 30 minutes. The samples were replaced with fresh dissolution medium of same quantity. The aliquots withdrawn were analyzed for drug content by taking absorbance at $274 \mathrm{~nm}$ using a UV spectrophotometer. \% drug release was calculated and plotted against time. The experiment was performed in triplicate.

\section{Statistical Analysis}

\section{Check point batch}

To confirm the validity of contour plot and equation generated by multiple regression analysis, check point batches were prepared in duplicate. The values of all possible combinations of three independent variables $\mathrm{X}_{1}, \mathrm{X}_{2}$ and $X_{3}$ were selected randomly. The results of the check point batches were compared with the response values of 
R1, R2, R3 and R4 obtained from the equation generated. The amount of Kyron T-314, CRP and Pearlitol SD 200 selected from contour plot and check point batches were prepared.

\section{$2^{4}$ factorial design.}

The magnitude of the coefficients represents the relative importance of each factor.

The best equation may be selected from Half-Normal plot. The multiple regression coefficients $\mathrm{R}^{2}$ are a measure of it. If values of $R^{2}=1$ or $0.91-0.99$, it indicates good fit. $R^{2}$ is sum of square due to regression/ sum of square without regression.

The general form of the MLRA model is represented as the following equation:

$\mathrm{R}=\mathrm{b}_{0}+\mathrm{b}_{1} \mathrm{X}_{1}+\mathrm{b}_{2} \mathrm{X}_{2}+\mathrm{b}_{3} \mathrm{X}_{3}+\mathrm{b}_{4} \mathrm{X}_{1} \mathrm{X}_{2}+\mathrm{b}_{5} \mathrm{X}_{1} \mathrm{X}_{3}+\mathrm{b}_{6} \mathrm{X}_{2} \mathrm{X}_{3}+$ $\mathrm{b}_{7} \mathrm{X}_{1}{ }^{2}+\mathrm{b}_{8} \mathrm{X}_{2}{ }^{2}+\mathrm{b}_{9} \mathrm{X}_{3}{ }^{2}$

Where $b_{0}$ is the intercept representing the arithmetic mean of all quantitative outcomes of 17 runs; $b_{1}-b_{9}$ are the coefficients computed from the observed experimental response values of $R ; X_{1}, X_{2}$ and $X_{3}$ are the coded values of the independent variables; $\mathrm{X}_{1} \mathrm{X}_{2}, \mathrm{X}_{1} \mathrm{X}_{3}, \mathrm{X}_{2} \mathrm{X}_{3}$ are interaction terms and $\left(\mathrm{X}_{1}\right)^{2},\left(\mathrm{X}_{2}\right)^{2},\left(\mathrm{X}_{3}\right)^{2}$ are quadratic terms.

The magnitude of the coefficients represents the relative importance of each factor.

Method also involves derivatization of regression fits using all possible combinations of independent variables. The best equation may be selected based on the fit and number of variables needed for it. The multiple regression coefficients $\mathrm{R}^{2}$ are a measure of it. If values of $\mathrm{R}^{2}=1$ or $0.91-0.99$, it indicates good fit. $\mathrm{R}^{2}$ is sum of square due to regression/ sum of square without regression.

\section{Statistical analysis of the data and validation of model:}

Statistically validity of the model was established on the basis of ANOVA provision provided in the Design Expert software 8.0.1.7. Using 5\% significance level, the model was considered significant, if the $\mathrm{p}$ value was less than 0.05 . For Orodispersible formulation designed to minimum disintegration and wetting time and maximum \% Drug release. So Orodispersible tablet was optimized with R1, R2 and R3. Comparative study was carried for comparison between marketed product and prepared optimized tablet. Comparative study performed on various evaluation parameters like hardness, wetting time, disintegration time, drug content and In-vitro dissolution study.

\section{RESULT AND DISCUSSION}

To enhance the dissolution of drug from Orodispersible tablets Loratadine and $\beta$ - cyclodextrin prepared by kneading method as described in our previous work ${ }^{11}$. The solubility was reported to be increased by 430 fold from $0.004 \mathrm{mg} / \mathrm{ml}$. The solid dispersion of the $\beta$ - cyclodextrin Loratadine complex in the molecular ratio of $1: 3$ was used. The screening for various super disintegrating agents was carried out in which crosspovidone, sodium starch glycolate, kyron T314, and cross carmellose sodium etc was used. The results from preliminary studies showed that formulations prepared with Crosspovidone and Kyron T314 as disintegrating agent has good correlation between the disintegrating time and wetting time. Hence, these two superdisintegrants were selected for further studies and employed in combination. The $2^{4}$ factorial was designed accordingly.

A two-level, four factor $2^{4}$ full factorial design was utilized for screening of independent variable from four variables. The response variables measured were disintegrating time and wetting time. The summary of set parameters is given in Table 2. In $2^{4}$ factorial design, four factors, the amount of super disintegrants, pore forming agent and hardness were evaluated. It was observed that formulations containing lower concentrations of super disintegrating agents showed disintegration time more than a minute compared to other formulations. Al though, it was found that no significant effect of hardness was observed on disintegration time. The least time taken for disintegration was by formulations F11, F13 and F15 where the amount of super disintegrants amount was higher. The entire primary batched in factorial design showed tablet friability under $1 \%$.

The quicker disintegration time may be attributed to faster water uptake by the tablet. Kyron T-314 and CRP act by porosity and capillary action (Wicking). In this liquid is drawn up or "wicked" in through capillary action and rupture the inter-particulate bonds causing the tablet to break apart. Moreover, compared with other super disintegrants Kyron T-314 and CRP showed better compressibility, high capillary activity pronounced hydration capacity, and little tendency to form gels. The tablets containing SSG took more time for disintegration compared to other super disintegrating agents used. This might be attributed to its slow swelling property of SSG. Precompression parameters for all different combinations were found to be acceptable where bulk density, tapped density and compressibility found to be in between 0.454 to 0.531 $\mathrm{g} / \mathrm{ml}, 0.329$ to $.0371 \mathrm{~g} / \mathrm{ml}$ and $9.09 \%$ to $18.4 \%$ respectively. The powder blend was found to have a good flow property which was also confirmed from the results of angle of repose and Hausner's ratio. The Angle of repose remained below $30^{\circ}$ for all preparation and Haursner's ratio was obtained in the range of 1.1 to 1.3 indicative of free flow with no cohesive forces present.

With the help of design expert software generated equations to quantify the effect of the formulation variables on the disintegrating time, wetting time.

The equation representing the quantitative effect of independent variables on;

Disintegration time (E1) $=27.63-57.87 \quad X_{1}-25.88 X_{2}-8.31 X_{3}$

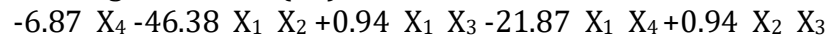
$-9.38 X_{2} X_{4}-19.38 X_{1} X_{2} X_{4}$

Wetting time $(E 2)=28.75-6.50 \quad X_{1}-35.75 \quad X_{2}+28.75 \quad X_{3}-$

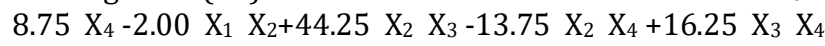
$+18.75 \mathrm{X}_{2} \mathrm{X}_{3} \mathrm{X}_{4}$

Considering p-value (level of significance) less than 0.05 , it was found that disintegration time (E1) was influenced significantly by $\mathrm{X}_{1}, \mathrm{X}_{2}, \mathrm{X}_{3}$ and $\mathrm{E} 2$ was influence significantly by $X_{1}, X_{2}, X_{3}$. On other hand, $X_{4}$ and their interaction were not able to give any significant effect on response variables.

It is evident from the equations that factor $\mathrm{X}_{1}$ (Kyron T-314), $\mathrm{X}_{2}$ (CRP), $\mathrm{X}_{3}$ (Pearlitol SD200) and their interactions term contribute negatively to E1 and E2 whereas $\mathrm{X}_{4}$ (Hardness) and their interactions have not significant effect on E1 and E2. That is suggestive of decrease in disintegration time and wetting time. Therefore, further optimization study for $\mathrm{X}_{1}, \mathrm{X}_{2}$ and $\mathrm{X}_{3}$ were carried out using Box-Behnken design. 
Table 1: Composition of Loratadine ODT tablet and levels used in $2^{4}$ Factorial design

\begin{tabular}{|c|c|c|c|c|}
\hline \multirow{2}{*}{ Ingredients } & \multirow{2}{*}{ Fixed level } & \multirow{2}{*}{ Factors } & \multicolumn{2}{|c|}{ Levels } \\
\hline & & & $\operatorname{Low}(-1)$ & High(+1) \\
\hline LRD: $\beta$-CD complex & 98 & $\mathrm{X}_{1}$ : Kyron T-314 & $2 \%$ & $6 \%$ \\
\hline Kyron T-314 & -- & $\mathrm{X}_{2}: \mathrm{CRP}$ & $5 \%$ & $10 \%$ \\
\hline CRP & -- & $\mathrm{X}_{3}:$ Pearlitol SD 200 & $15 \%$ & $25 \%$ \\
\hline Pearlitol SD 200 & -- & $\mathrm{X}_{4}:$ Hardness & $3 \mathrm{~kg} / \mathrm{cm}^{2}$ & $4 \mathrm{~kg} / \mathrm{cm}^{2}$ \\
\hline MCC & q.s & & & \\
\hline Aspartame & 4 & & & \\
\hline Talc & 2 & & & \\
\hline Mg. Stearate & 1 & & & \\
\hline
\end{tabular}

Table 2: 24 Factorial design matrix and response

\begin{tabular}{|c|c|c|c|c|c|c|}
\hline Batch code & $\mathbf{X}_{\mathbf{1}}$ & $\mathbf{X}_{\mathbf{2}}$ & $\mathbf{X}_{\mathbf{3}}$ & $\mathbf{X}_{\mathbf{4}}$ & $\begin{array}{c}\text { R1 } \\
\text { (Disintegration time) (sec) } \\
\mathbf{\pm} \text { SD }\end{array}$ & $\begin{array}{c}\text { R2 (Wetting time) } \\
\text { (sec) } \pm \text { SD }\end{array}$ \\
\hline $\mathrm{F}_{1}$ & -1 & -1 & -1 & 1 & $64 \pm 2.0$ & $68 \pm 3.08$ \\
\hline $\mathrm{F}_{2}$ & +1 & +1 & -1 & -1 & $47 \pm 3.2$ & $34 \pm 3.21$ \\
\hline $\mathrm{F}_{3}$ & +1 & -1 & +1 & +1 & $53 \pm 1.5$ & $59 \pm 3.1$ \\
\hline $\mathrm{F}_{4}$ & +1 & -1 & -1 & -1 & $51 \pm 1.5$ & $62 \pm 2.5$ \\
\hline $\mathrm{F}_{5}$ & -1 & +1 & -1 & -1 & $57 \pm 2.2$ & $48 \pm 2.0$ \\
\hline $\mathrm{F}_{6}$ & -1 & -1 & 1 & +1 & $44 \pm 1.5$ & $64 \pm 2.5$ \\
\hline $\mathrm{F}_{8}$ & -1 & +1 & -1 & +1 & $58 \pm 1.3$ & $48 \pm 1.1$ \\
\hline $\mathrm{F}_{9}$ & -1 & +1 & +1 & +1 & $44 \pm 2.0$ & $59 \pm 2.0$ \\
\hline $\mathrm{F}_{10}$ & -1 & -1 & -1 & +1 & $51 \pm 2.3$ & $67 \pm 2.5$ \\
\hline $\mathrm{F}_{12}$ & +1 & +1 & -1 & -1 & $62 \pm 1.6$ & $29 \pm 2.3$ \\
\hline $\mathrm{F}_{13}$ & +1 & -1 & +1 & -1 & $24 \pm 1.9$ & $39 \pm 2.7$ \\
\hline $\mathrm{F}_{14}$ & -1 & +1 & +1 & 1 & $33 \pm 1.7$ & $29 \pm 1.6$ \\
\hline $\mathrm{F}_{15}$ & +1 & +1 & +1 & -1 & $25 \pm 1.8$ & $39 \pm 2.9$ \\
\hline $\mathrm{F}_{16}$ & -1 & -1 & +1 & -1 & $35 \pm 1.6$ & $33 \pm 2.5$ \\
\hline
\end{tabular}

$\mathrm{X}_{1}$ code for amount of Superdisintegrant (Kyron T-314), $\mathrm{X}_{2}$ code for amount of Superdisintegrant (CRP), $\mathrm{X}_{3}$ code for amount of pore-forming agent (Pearlitol SD 200), $\mathrm{X}_{4}$ code for Hardness $\left(\mathrm{kg} / \mathrm{cm}^{2}\right)$

\section{Statistical analysis of BoxBehnken Design}

A three-factor, three-level Box-Behnken design was utilized for optimization of the Loratadine Orodispersible tablet. The dependent variables measured were disintegrating time, wetting time, Cumulative \% drug release at 20 min (Q20). The composition and responses of the Box-Behnken design are shown in Table 3 . The pre compression parameters evaluated are shown in Table 4. Among the different batches prepared according to Box behnken design, Disintegration time, wetting time, drug release (Q 20), friability \& hardness was found in the range of $23 \pm 2.5$ to $59 \pm 2.6,27 \pm 0.5$ to 66.3 $\pm 3.0,86.1 \pm 0.6$ to $96.7 \pm 0.5,0.3$ to $0.7 \%$, and 3.4 to 4.2 $\mathrm{Kg} / \mathrm{cm}^{2}$ respectively. FB1, FB9 and $\mathrm{FB} 15$ showed most suitable parameters in order of FB15>FB1>FB9 with FB15 showing least disintegration time of $23 \mathrm{sec}$ and wetting time of $27 \mathrm{sec}$. The percentage friability was in between 0.3 to .7 $\%$ that is very much under the limits specified in pharmacopeia. With hardness of nearly 4 and friability less than 0.7 percent all formulation showed good mechanical strength of tablets. It was also noted that higher amount of Pearlitol contributed in achieving better friability.

The disintegration time for all formulation from FB1 to FB17 was found to be less than a minute except formulation batches FB2, FB7 and FB13. Surface plot of the effect of CRP and Kyron T314 on disintegration time is shown in Figure 1 (a,b). The disintegration time of tablet was found to decrease when amount of CRP and KT were increased. S chaturvedi et al reported the faster disintegrating effect of KT at higher level when compared to Crosscarmellose for the direct compressible fast dissolving tablet containing losartan potassium ${ }^{17}$. With the help of MLRA, Design expert software 8.0.7.1 generated equations to quantify the effect of the formulation variables on the disintegrating time, wetting time, cumulative $\%$ drug release at $20 \mathrm{~min}$. 
Table 3: Box-Behnken design matrix and response

\begin{tabular}{|c|c|c|c|c|c|c|c|c|c|c|}
\hline \multicolumn{7}{|c|}{ Box-Behnken design } & & & & \\
\hline $\begin{array}{c}\text { Batch } \\
\text { code }\end{array}$ & $\mathbf{X}_{\mathbf{1}}$ & & $\mathbf{X}_{\mathbf{2}}$ & & $\mathbf{X}_{\mathbf{3}}$ & & $\begin{array}{c}\text { R1 } \\
\text { (DT) }\end{array}$ & $\begin{array}{c}\text { R2 } \\
\text { (WT) }\end{array}$ & $\begin{array}{c}\text { R3 } \\
\text { (Q20) }\end{array}$ & $\begin{array}{c}\text { R4 } \\
\text { (Friability) }\end{array}$ \\
\hline FB1 & -1 & 4.00 & 0 & 10.00 & 0 & 25.00 & $28 \pm 1.1$ & $33 \pm 0.5$ & $95.1 \pm 0.4$ & $0.45 \pm 0.04$ \\
\hline FB2 & +1 & 2.00 & -1 & 5.00 & 0 & 20.00 & $70 \pm 2.6$ & $63 \pm 1.5$ & $88.7 \pm 0.6$ & $0.52 \pm 0.06$ \\
\hline FB3 & 0 & 2.00 & -1 & 7.50 & +1 & 25.00 & $38 \pm 1.5$ & $43 \pm 2.5$ & $93.4 \pm 0.6$ & $0.35 \pm 0.10$ \\
\hline FB4 & 0 & 2.00 & 0 & 10.00 & 0 & 20.00 & $45 \pm 2.4$ & $50 \pm 2.9$ & $93.6 \pm 0.4$ & $0.56 \pm 0.01$ \\
\hline FB5 & -1 & 6.00 & +1 & 7.50 & 0 & 15.00 & $49 \pm 2.6$ & $52 \pm 2.1$ & $92.3 \pm 1.3$ & $0.61 \pm 0.07$ \\
\hline FB6 & 0 & 4.00 & 0 & 7.50 & 0 & 20.00 & $45 \pm 1.1$ & $50 \pm 3.4$ & $93.6 \pm 0.7$ & $0.56 \pm 0.02$ \\
\hline FB7 & -1 & 4.00 & 0 & 5.00 & +1 & 15.00 & $68 \pm 1.3$ & $66 \pm 3.4$ & $86.1 \pm 0.6$ & $0.62 \pm 0.04$ \\
\hline FB8 & 0 & 4.00 & +1 & 7.50 & +1 & 20.00 & $45 \pm 1.5$ & $50 \pm 2.6$ & $92.5 \pm 0.3$ & $0.56 \pm 0.04$ \\
\hline FB9 & 0 & 6.00 & 0 & 10.00 & 0 & 20.00 & $45 \pm 2.4$ & $50 \pm 2.9$ & $93.6 \pm 0.4$ & $0.56 \pm 0.01$ \\
\hline FB10 & 0 & 4.00 & 0 & 7.50 & 0 & 20.00 & $45 \pm 2.4$ & $50 \pm 2.9$ & $93.6 \pm 0.4$ & $0.56 \pm 0.01$ \\
\hline FB11 & +1 & 4.00 & 0 & 10.00 & -1 & 15.00 & $50 \pm 2.8$ & $53 \pm 2.5$ & $95.3 \pm 0.5$ & $0.70 \pm 0.03$ \\
\hline FB12 & 0 & 4.00 & 0 & 7.50 & 0 & 20.00 & $45 \pm 2.4$ & $50 \pm 2.9$ & $93.6 \pm 0.4$ & $0.56 \pm 0.01$ \\
\hline FB13 & 0 & 2.00 & -1 & 7.50 & -1 & 15.00 & $66 \pm 2.6$ & $63 \pm 3.1$ & $92.4 \pm 0.6$ & $0.59 \pm 0.02$ \\
\hline FB14 & +1 & 4.00 & 0 & 7.50 & +1 & 20.00 & $45 \pm 1.5$ & $50 \pm 2.5$ & $93.6 \pm 0.3$ & $0.56 \pm 0.10$ \\
\hline FB15 & +1 & 6.00 & +1 & 7.50 & 0 & 25.00 & $23 \pm 2.5$ & $27 \pm 0.5$ & $96.7 \pm 0.4$ & $0.34 \pm 0.04$ \\
\hline FB16 & 0 & 4.00 & +1 & 5.00 & -1 & 25.00 & $38 \pm 1.5$ & $46 \pm 1.1$ & $89.8 \pm 0.6$ & $0.31 \pm 0.03$ \\
\hline FB17 & -1 & 6.00 & 0 & 5.00 & -1 & 20.00 & $46 \pm 1.15$ & $55 \pm 3.0$ & $87.8 \pm 0.4$ & $0.49 \pm 0.02$ \\
\hline X1
\end{tabular}

$\mathrm{X}_{1}$ code for amount of Superdisintegrant (Kyron T-314), $\mathrm{X}_{2}$ code for amount of Superdisintegrant (CRP), $\mathrm{X}_{3}$ code for amount of pore-forming agent (Pearlitol SD 200)

Table 4: Micromeritic properties of powder blend of LRD Orodispersible tablets

\begin{tabular}{|c|c|c|c|c|c|}
\hline Batch No & $\begin{array}{c}\text { Angle of Repose } \\
(\boldsymbol{\theta})\end{array}$ & $\begin{array}{c}\text { Bulk Density } \\
(\mathbf{g} / \mathbf{m l})\end{array}$ & $\begin{array}{c}\text { Tapped Density } \\
(\mathbf{g} / \mathbf{m} \mathbf{)}\end{array}$ & $\begin{array}{c}\text { Compressibility } \\
\text { Index (\%) }\end{array}$ & Hausner's ratio \\
\hline FB1 & $24.84^{\circ}$ & 0.45 & 0.51 & 9.09 & 1.1 \\
\hline FB2 & $28.52^{\circ}$ & 0.41 & 0.52 & 20.83 & 1.26 \\
\hline FB3 & $22.83^{\circ}$ & 0.41 & 0.52 & 24.30 & 1.31 \\
\hline FB4 & $25.60^{\circ}$ & 0.45 & 0.55 & 18.18 & 1.22 \\
\hline FB5 & $29.16^{\circ}$ & 0.37 & 0.47 & 22.22 & 1.28 \\
\hline FB6 & $26.11^{\circ}$ & 0.38 & 0.45 & 15.38 & 1.18 \\
\hline FB7 & $32.00^{\circ}$ & 0.37 & 0.47 & 22.22 & 1.28 \\
\hline FB8 & $26.11^{\circ}$ & 0.38 & 0.45 & 15.38 & 1.18 \\
\hline FB9 & $23.68^{\circ}$ & 0.40 & 0.45 & 12.08 & 1.13 \\
\hline FB10 & $26.11^{\circ}$ & 0.38 & 0.45 & 15.38 & 1.18 \\
\hline FB11 & $25.64^{\circ}$ & 0.35 & 0.43 & 17.85 & 1.21 \\
\hline FB12 & $26.11^{\circ}$ & 0.38 & 0.45 & 15.38 & 1.18 \\
\hline FB13 & $30.34^{\circ}$ & 0.43 & 0.52 & 24.12 & 1.31 \\
\hline FB14 & $26.11^{\circ}$ & 0.38 & 0.45 & 15.38 & 1.18 \\
\hline FB15 & $24.87^{\circ}$ & 0.41 & 0.47 & 12.50 & 1.14 \\
\hline FB16 & $23.19^{\circ}$ & 0.43 & 0.52 & 13.04 & 1.15 \\
\hline FB17 & $26.09^{\circ}$ & 0.41 & 0.49 & 16.66 & \\
\hline
\end{tabular}

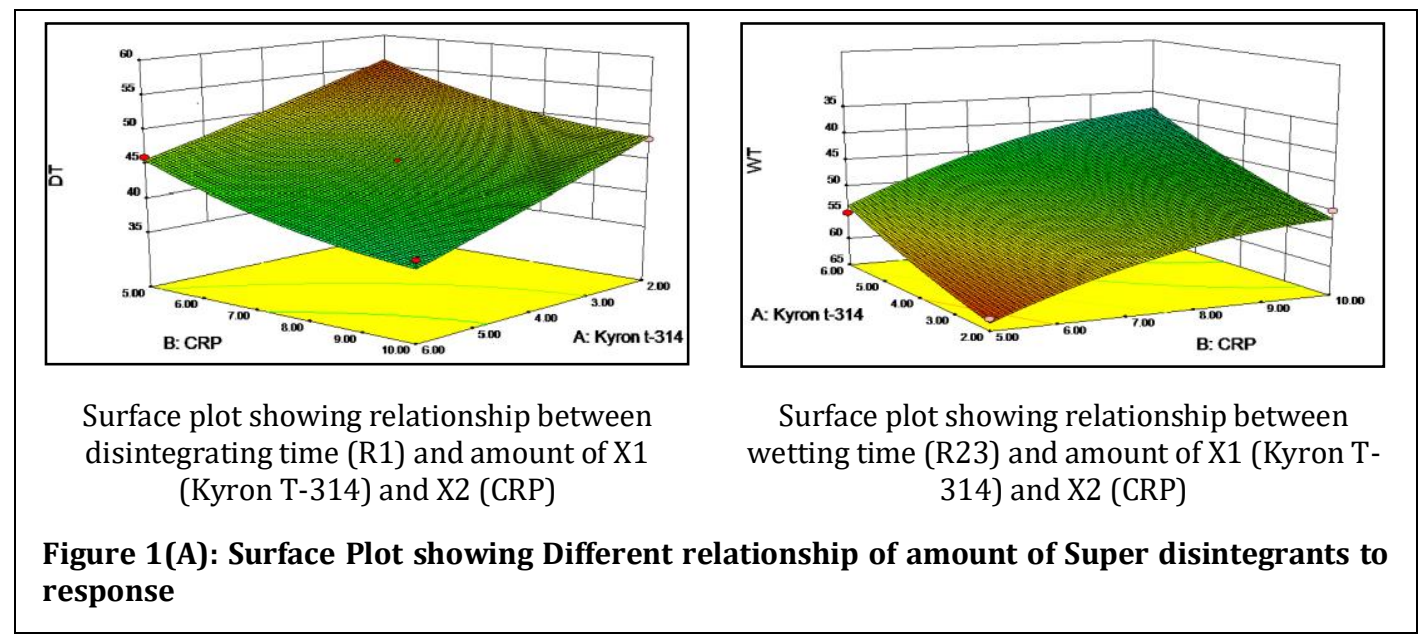




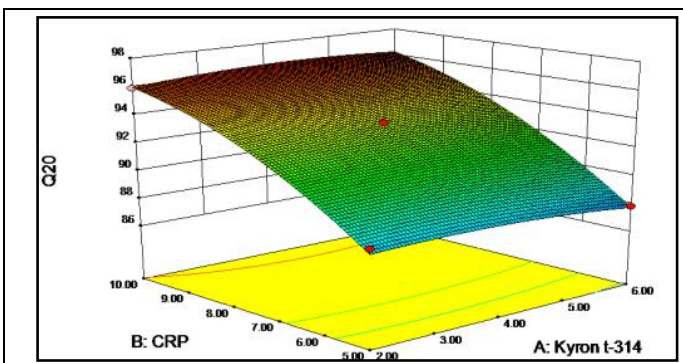

Surface plot showing relationship between Q20 (R3) and amount of X1 (Kyron T-314) and X2 (CRP)

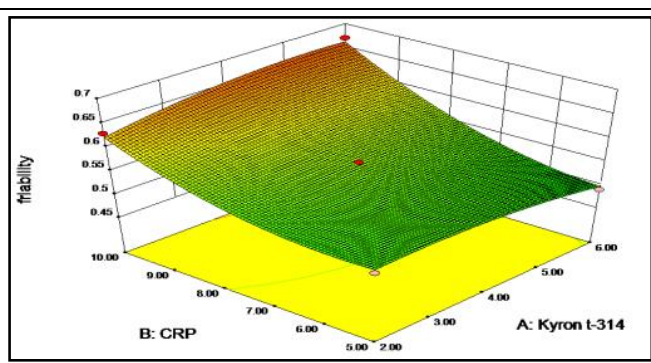

Surface plot showing relationship between friability (R4) and amount of X1 (Kyron T-314) and X2 (CRP

Figure 1(B): Surface Plot showing Different relationship of amount of Super disintegrants to response

The equation representing the quantitative effect of independent variables on;

Disintegration Time (R1) $=45.00-5.50 \mathrm{X}_{1}-4.12 \mathrm{X}_{2}-11.13$ $\mathrm{X}_{3}-0.25 \mathrm{X}_{1} \mathrm{X}_{2}-1.25 \mathrm{X}_{1} \mathrm{X}_{3}-0.50 \mathrm{X}_{2} \mathrm{X}_{3}+0.25 \mathrm{X}_{1}^{2}+1.50$ $\mathrm{X}_{2}{ }^{2}-3.00 \mathrm{X}_{3}^{2}$

Wetting Time (R2) $=50.00-5.75 X_{1}-6.88 X_{2}-10.63 X_{3}-$ $0.75 \mathrm{X}_{1} \mathrm{X}_{2}-1.25 \mathrm{X}_{1} \mathrm{X}_{3}+0.000 \mathrm{X}_{2} \mathrm{X}_{3}-0.75 \mathrm{X}_{1}^{2}+2.50 \mathrm{X}_{2}^{2}-$ $3.00 \mathrm{X}_{3}^{2}$

Q20 (R3) = + $93.60-0.087 X_{1}+4.03 X_{2}+0.69 X_{3}+0.22 X_{1}$ $\mathrm{X}_{2}+0.10 \mathrm{X}_{1} \mathrm{X}_{3}-1.08 \mathrm{X}_{2} \mathrm{X}_{3}-0.37 \mathrm{X}_{1}{ }^{2}-1.15 \mathrm{X}_{2}{ }^{2}-0.27 \mathrm{X}_{3}{ }^{2}$

Friability (R4) $=0.56+2.500 \mathrm{E}-003 \mathrm{X}_{1}+0.065 \mathrm{X}_{2}-0.14 \mathrm{X}_{3}$ $+0.017 \mathrm{X}_{1} \mathrm{X}_{2}-7.500 \mathrm{E}-003 \mathrm{X}_{1} \mathrm{X}_{3}+0.018 \mathrm{X}_{2} \mathrm{X}_{3}-0.014 \mathrm{X}_{1}^{2}$ $+0.031 \mathrm{X}_{2}^{2}-0.074 \mathrm{X}_{3}^{2}$

The polynomial equations comprise the coefficients for intercept, first-order main effects, interaction terms and higher order effects. Positive sign against the individual term indicated synergistic effect while negative sign indicated antagonistic effect of the factors.

The values of the coefficients $\mathrm{X}_{1}, \mathrm{X}_{2} \& \mathrm{X}_{3}$ relate to the main effects of these variables on the corresponding response.

It was evident from the equations that factor $\mathrm{X}_{1}$ (Kyron $\mathrm{T}$ 314 ) and their interactions term contribute negatively to R1,
$\mathrm{R} 2$ and R3 whereas positively to R4. $\mathrm{X}_{2}$ (Crospovidone) and their interaction terms contribute negatively to R1, R2 whereas positively to R3 and R4. $\mathrm{X}_{3}$ (Pearlitol SD200) and their interaction terms contributes negatively R1, R2 and R3 and positively to $\mathrm{R} 4$.

Considering p-value (level of significance) less than 0.05 , it was found that $\mathrm{R} 1$ was influenced significantly by $\mathrm{X}_{1}, \mathrm{X}_{2}, \mathrm{X}_{3}$, $\mathrm{X}_{2}{ }^{2}$ and $\mathrm{X}_{3}{ }^{2}, \mathrm{R} 2$ was influence significantly by $\mathrm{X}_{1}, \mathrm{X}_{2}, \mathrm{X}_{3}, \mathrm{X}_{2}{ }^{2}$ and $\mathrm{X}_{3}{ }^{2}, \mathrm{R} 3$ by $\mathrm{X}_{2}, \mathrm{X}_{3}, \mathrm{X}_{2} \mathrm{X}_{3}, \mathrm{X}_{2}{ }^{2}, \mathrm{X}_{3}{ }^{2}$. Remaining terms had non- significant ( $p>0.05$ ) contribution to the response variables.

The three factors Kyron T-314, CRP and Pearlitol SD200 were selected as independent variables and Disintegration time (DT), Wetting (WT) and \% drug release at $20 \mathrm{~min}$ (Q20) were set as response variable in Box-Behnken design. Total of 17 batches [FB1-FB17] were prepared and evaluation was carried out. From All batches FB15 showed good result i.e DT of $23 \mathrm{sec}$, WT of $27 \mathrm{sec}$ and Q20 of $96.7 \%$ and regarded as optimized formulation.

Box-Behnken design gave regression equation for response for selected variables within selected range selected for those variables. Validity of these equations is confirmed within those selected range by taking check point batches at particular value of those selected variables.

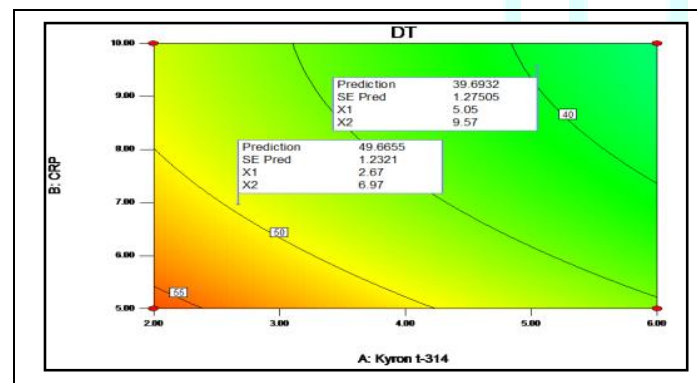

Contour plot for Disintegration time with check point batch value

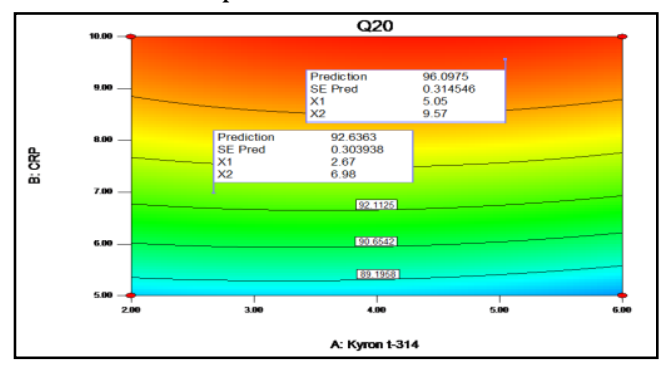

Contour plot for Q20 (R3) with check point batch value

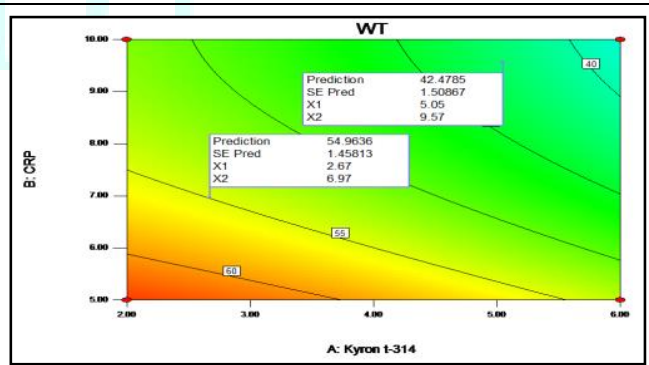

Contour plot for wetting time (R2) with check point batch value

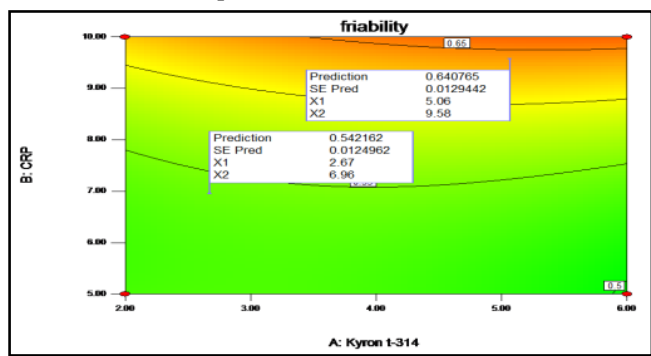

Contour plot for Friability (R4) with check point batch value

Figure 2: Contour plot for Disintegration time with check point batch value 
The $\%$ relative error obtained from checkpoint batch was in the range of 3.426-1.349. It can be seen that in all cases there was a reasonable agreement of predicted values and experimental values, since low values of the relative error were found. This confirmed the role of a derived reduced polynomial equation, proved the validity of the model and ascertained the effects of Kyron T-314, CRP and Pearlitol SD200 on disintegrating time, cumulative $\%$ drug release at $20 \mathrm{~min}$, wetting time and friability. The contour plots are shown in Figure 2.

\section{Surface plot for each response}

Surface plots were obtained for the measured response based on the model using Design-Expert $\AA$ software. A response surface graph shows the response as a function of factor level.

Three dimensional response surface graphs for R1 and R2 were drawn for two factors only keeping the third factor constant. Significant influences of each independent variable on depend-ent variables are observed from all response surface graphs. The relationship between the independent variables and the response can be further explained by using these surface plots.

\section{In-vitro Dissolution study}

The drug release was expected to be faster as the drug $\beta$ cyclodextrin complex was used in the preparation of Orodispersible tablet. All the formulation showed cumulativ drug release of greater than $85 \%$ in 20 mins. Formulation batches FB1, FB11 and FB15 showed more than 95\% drug release in 20 mins. The formulation batches FB16, FB 17 and FB2 showed lesser dissolution rate below 90\%. It was observed that amount of disintegrating agent influences the dissolution rate and disintegrating time. Higher concentration of disintegrating agent resulted lower disintegration and wetting time. The graphical representation of in vitro drug release in shown in Figure 3.

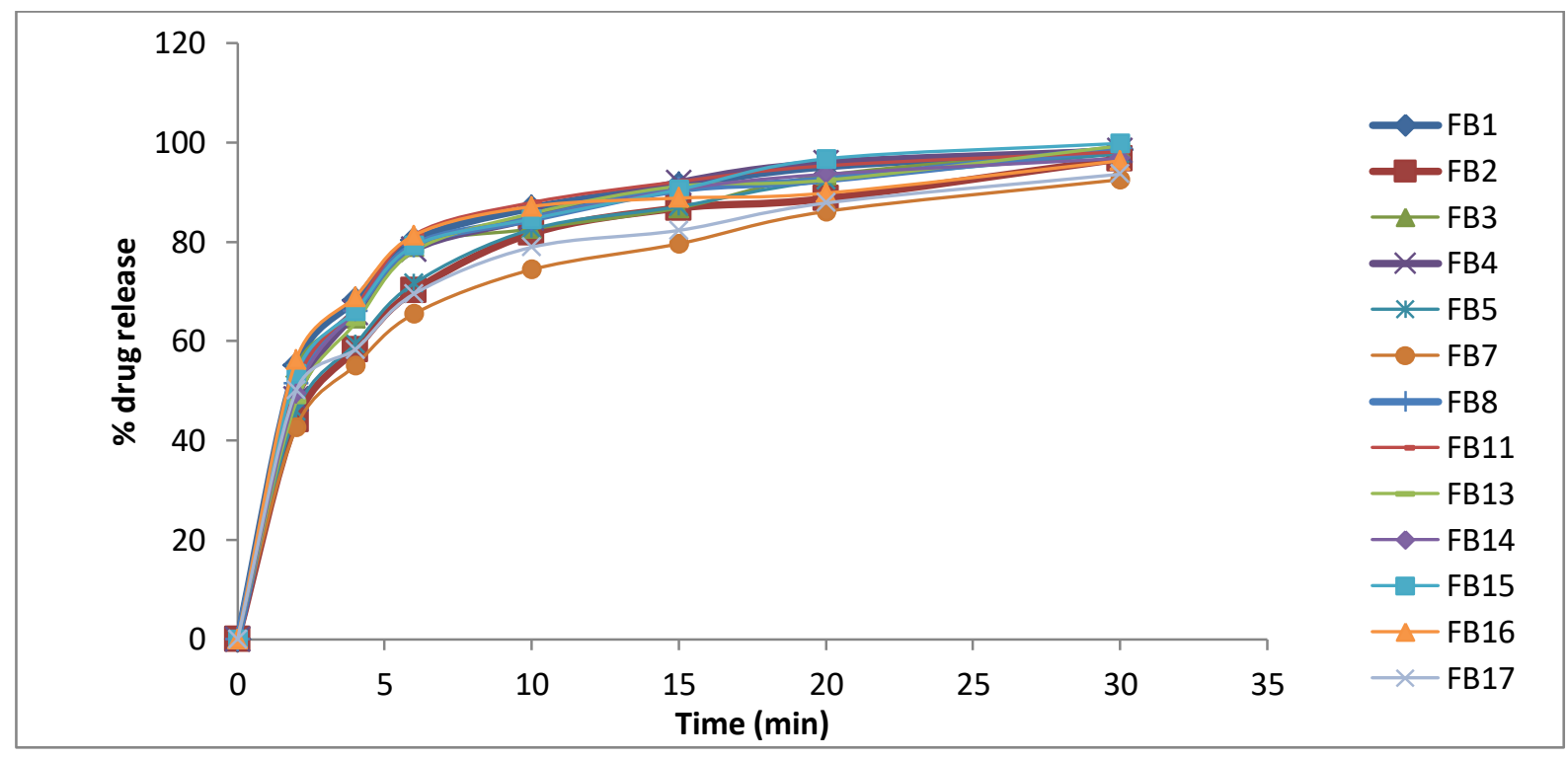

Figure 3: In-vitro drug release of batches FB1-FB17

\section{Optimized Formulation of Loratadine Orodispersible tablet:-}

The selection of best formulation depends on minimum disintegration \& wetting time, maximum $\%$ drug release at 20 min (Q20). So, above criteria for optimized formulation was meeting with batch FB15 which have disintegration time of $23 \mathrm{sec}$, wetting time of $27 \mathrm{sec}$, friability of 0.34 and drug release of $94.7 \%$ at $20 \mathrm{~min}$. So the batch FB15 was found to be the best fit formulation among all other batches.
The optimized Orodispersible tablet (FB15) when compared with Lorfast melt tab (cadila pharma) showed no difference in the hardness and drug content, comparative data are shown in Table 6. However, FB15 showed reduced disintegration time and wetting time. FB15 batch found to release the drug much faster than marketed product (LORFAST MELTAB). Hence it can be concluded that the formulated LRD Orodispersible tablets were superior to marketed LORFAST MELTAB to achieve fast therapeutic response in the form of orodispersible tablet.

Table 5: Experimental values and predicted value of the check point batches

\begin{tabular}{|l|l|l|l|l|}
\hline Response & Batch & Predicted value & Experimental value & \% Relative error \\
\hline \multirow{2}{*}{ Disintegration time } & C1 & 49.66 & 50.33 & -1.349 \\
\cline { 2 - 5 } & C2 & 39.69 & 38.33 & 3.426 \\
\hline \multirow{2}{*}{ Wetting time } & C1 & 42.47 & 43 & -1.247 \\
\cline { 2 - 5 } & C2 & 54.96 & 54.33 & 1.146 \\
\hline \multirow{2}{*}{ Q20 } & C1 & 92.63 & 91.3 & 1.435 \\
\cline { 2 - 5 } & C2 & 96.09 & 95.1 & 1.030 \\
\hline \multirow{2}{*}{ Friability } & C1 & 0.542 & 0.543 & -0.184 \\
\cline { 2 - 5 } & C2 & 0.640 & 0.642 & -0.312 \\
\hline
\end{tabular}


Table 6: Comparative evaluation study with LORFAST MELTAB (n=3)

\begin{tabular}{|c|c|c|}
\hline Evaluation & Marketed tablet (Lorfast melt tab) & Batch FB15 \\
\hline Hardness (kg/cm ${ }^{2}$ ) & $3.0 \pm 0.1$ & $3.4 \pm 0.1$ \\
\hline Friability (\%) & $0.64 \pm 0.07$ & $0.34 \pm 0.03$ \\
\hline Wetting time (second) & $36 \pm 3.9$ & $27 \pm 1.8$ \\
\hline Disintegration time (second) & $29 \pm 3.3$ & $23 \pm 1.6$ \\
\hline Drug content (\%) & $99.1 \pm 3.4$ & $98.6 \pm 2.8$ \\
\hline Q20 (\%) & $62.9 \pm 2.0$ & $94.7 \pm 2.4$ \\
\hline
\end{tabular}

\section{CONCLUSION:}

Orodispersible tablet prepared using combination of two superdisintegrants, Kyron 314 and CRP, showed satisfactory tablet properties. The factorial design and box Behnken design revealed that superdisintegrant concentration has significant influence on wetting time, disintegration time, friability and drug release from Orodispersible tablet. The superdisintegrant combination and use of Mannitol resulted in optimal tablet properties. Formulations FB15 was chosen as optimal formulations that fulfilled specific requirement of ODT. Being advantageous over wet granulation, the Orodispersible tablets of Loratidine were successfully prepared by direct compression method using Loratidine- $\beta$ CD complex and super disintegrating agents. The drug $\beta-C D$ complex along with faster dispersion could increase bioavailability of drug.

\section{REFERENCES:}

1. Habib W, Khankari R, and Hontz J, Fast dissolve drug delivery systems. Critical Review Therapeutic Drug carrier system, 2000; 17(1): 61-72.

2. Ghosh TK, Chatterjee DJ and Pfister, WR, Quick dissolving oral dosage forms: scientific and regulatory considerations from a clinical pharmacology and biopharmaceutical perspective. CRC press, New York. 2005. P. 337-356.

3. Kaushik D, Dureja H, Saini TR, Orally disintegrating tablets: An overview of melt-in mouth tablet technologies and techniques. Tablets and Capsules, 2004; 2(4): 30-36.

4. Kamboj M, Goyal S, Rakha P, Arora G, Dureja H And Nagpal M, Formulation and evaluation of metformin oro-dispersible tablets, Acta Poloniae Pharmaceutica Drug Research, 2011; 68( 5): 717-723.

5. Gissinger D and Stamm A, Comparative Evaluation of the Properties of. Some Tablet Disintegrants. Drug Development and Industrial Pharmacy, 1980; 6: 511-36.
6. Bi Y, Preparation and evaluation of compressed tablet rapidly disintegrating in the oral cavity, Chemical and Pharmaceutical Bulletin, 1996; 44(11):2121-2127.

7. BASF Technical Literature, Kollidone Polyvinylpyrrolidone for pharmaceutical industry, BASF Aktiengesellschaft, Fine Chemicals, D- 67056, Ludwigshafen; March 1998 (4th edition).,

8. European pharmacopoeia, 6th edition,vol.1, 2008. P. 750.

9. Kay GG, Harris AG, Loratadine: a non-sedating antihistamine. Review of its effects on cognition, psychomotor performance, mood and sedation. Clinical Experimental Allergy, 1999; 3:147-150.

10. Kreutner W, Chapman RW, Gulbenkian A, Siegel MI,. Antiallergic activity of loratadine, a non-sedating antihistamine, Allergy,1987; 42(1): 57-63.

11. Kundawala AJ, Patel P, Solubility Enhancement of Loratadine by Solid Dispersion Techniques. International Journal of Chemtech and Research, 2017; 10(7): 207-217.

12. Cooper J, Gunn C, Powder flow and compaction. In: Carter, S.J. (Ed.), Tutorial Pharmacy. CBS Publishers and Distributors, New Delhi, India, 1986. P. 211-233.

13. Shah D, Shah Y, Rampradhan M, Development and evaluation of controlled release diltiazem hydrochloride microparticles using cross-linked poly (vinyl alcohol). Drug Development and Industrial Pharmacy, 1997; 23: 567-574.

14. United States Pharmacopeia 24/NF19, 2000. The Official Compendia of Standards. Asian Rockville, M.D. (Ed.), United States Pharmacopoeia Convention Inc, pp. 1913-1914.

15. Banker GS, Anderson NRI, In:Lachman,L., Lieberman,H.A., Kanig, J.L. (Eds.), The Theory and Practice of Industrial Pharmacy, third ed. Varghese Publishing House, Mumbai, 1987. P. 293-299.

16. Tejvir K, Bhawandeep G, Sandeep K, Gupta GD, Mouth dissolving tablets: a novel app to drug delivery. International journal of current pharmaceutical research, 2011; 3 (1): 1-7.

17. Chaturvedi S, Agrawal V, Singh S, Impact of superdisintegrants on the release of oro-dispersible tablets of losartan potassium: A comparative analysis. Der Pharmacia Lettre, 2012; 4 (6):1768-1776. 